\title{
Guided imagery relaxation therapy on preoperative anxiety: why did the authors omit pain data?
}

\author{
Richard Gray ${ }^{1}$ \\ (1D) https://orcid.org/0000-0001-9694-4206 \\ Ellie Brown ${ }^{2}$ \\ (D) https://orcid.org/0000-0002-1645-5443
}

\author{
Letter to the Editor regarding the article "Felix MMS, \\ Ferreira MBG, Oliveira LF, Barichello E, Pires PS, \\ Barbosa MH. Guided imagery relaxation therapy on \\ preoperative anxiety: a randomized clinical trial. \\ Rev. Latino-Am. Enfermagem. 2018;26:e3101. DOI: \\ http://dx.doi.org/10.1590/1518-8345.2850.3101."
}

Dear editors, we read with interest the triple-blind trial of guided imagery relaxation on preoperative anxiety by Felix ${ }^{(1)}$ and published in Revista Latino-Americana de Enfermagem.

The authors recruited 24 patients receiving bariatric surgery that were randomised to receive standard of care plus 20 minutes of guided imagery relaxation $(n=12)$ or standard care alone $(n=12)$. Two outcomes were reported in the published manuscript: state anxiety and cortisol level. The authors concluded that guided imagery relaxation is effective at reducing state anxiety and blood cortisol in the preoperative period ${ }^{(1)}$. The trial was prospectively registered with the Brazilian Clinical Trials Registry (RBR-5qywrf). According to the registry entry, the primary outcomes of the trial were postoperative pain and cortisol. Anxiety is listed as a secondary outcome. As far as we can determine, the pain data have not been reported in the manuscript. One of the primary reasons trials need to be registered is to ensure that authors do not selectively report or omit outcomes that may misrepresent the effectiveness of an experimental intervention ${ }^{(2)}$. The authors must make the pain data available and justify why these data were initially omitted from the manuscript. As part of the peer-review process reviewers and editors should have reconciled the trial registry entry with the submitted manuscript; it would be informative if the editors could confirm this was done. If this was done can the editors, then explain why the authors were not challenged about the omission of pain data. Alternatively, if the manuscript and registry entry were not checked the editors may need to consider if there has been a failure of the Journal's editorial and peer review processes.

\section{How to cite this article}

Gray R, Brown E. Guided imagery relaxation therapy on preoperative anxiety: why did the authors omit pain data? Rev. Latino-Am. Enfermagem. 2020;28:e3382. [Access † + _ ] ; Available in: DOI: http://dx.doi.org/10.1590/1518-8345.4716.3382. month day year 
In our opinion, the omission of the pain data means that the reporting of the trial by Felix ${ }^{(1)}$ is incomplete and inconsistent with the trial registry entry. Consequently, the reported conclusions are unsound. We look forward to a response from both the study authors and journal editors.

\section{References}

1. Felix MMS, Ferreira MBG, Oliveira LF, Barichello E, Pires PS, Barbosa MH. Guided imagery relaxation therapy on preoperative anxiety: a randomized clinical trial. Rev. Latino-Am. Enfermagem. [Internet]. 2018 Nov 29 [cited Jun 25, 2020];26. Available from: https://www.ncbi.nlm.nih.gov/pmc/articles/PMC6280172/

2. Scott A, Rucklidge JJ, Mulder RT. Is Mandatory Prospective Trial Registration Working to Prevent Publication of Unregistered Trials and Selective Outcome Reporting? An Observational Study of Five Psychiatry Journals That Mandate Prospective Clinical Trial Registration. PLOS One. 2015 Aug 19;10(8):e0133718.

Response of the authors of the article "Felix MMS, Ferreira MBG, Oliveira LF, Barichello E, Pires PS, Barbosa MH. Guided imagery relaxation therapy on preoperative anxiety: a randomized clinical trial. Rev. Latino-Am. Enfermagem. 2018;26:e3101. DOI: http://dx.doi.org/10.1590/1518-8345.2850.3101."

The question sent to the journal's Editor about the published article is mainly based on the statement that the primary outcome of the clinical study record was the assessment of pain intensity, and that the data referring to pain is not mentioned in the published article. Anxiety and blood cortisol levels are described as a secondary outcome.

As noted in the title of the published article: "Image-guided relaxation therapy on preoperative anxiety: a randomized clinical trial" and in the objective described "to evaluate the effect of image-guided relaxation therapy on state-anxiety and cortisol in the immediate preoperative period in patients undergoing bariatric surgery by videolaparoscopy", this article intended to present the results related to these variables: anxiety and cortisol. It should be noted that at the end of the manuscript there is a description that the article was extracted from the PhD thesis entitled: "Image-guided relaxation therapy on anxiety and pain in patients who underwent bariatric surgery: a randomized clinical trial", presented to the Federal University of Triângulo Mineiro, Uberaba, MG, Brazil; therefore, it is the publication of part of the results obtained in the thesis.

The pain outcome was not described in the objective of the article as it will be described in another publication, which the authors have been preparing, which does not mean an intentional omission on the part of the authors, but a decision to publish the results independently in a specialized journal.

The statement described by the contestant that the omission of this data makes the publication inconsistent with the registration of the clinical trial does not proceed, since the outcome was presented in the thesis; however, at the time of submission of the publication, it was decided to treat the results regarding pain intensity in another submission.

Sincerely,

The authors.

Also, access the editorial "Commitment to integrity and transparency in research", DOI: http://dx.doi.org/10.1590/1518-8345.0000.3403. 